\title{
Low-temperature degradation of high-strength Y-TZP (yttria-stabilized tetragonal zirconia polycrystal)
}

\author{
Katsunori FURUYA ${ }^{1}$, Shinji TAKEMOTO², Shuichiro YAMASHITA¹, Hideshi SEKINE², Yasutomo YAJIMA ${ }^{4}$ \\ and Masao YOSHINARI ${ }^{5}$

\begin{abstract}
${ }^{1}$ Department of Removable Partial Prosthodontics, Tokyo Dental College, 2-9-18 Kandamisaki-cho, Chiyoda-ku, Tokyo 101-0061, Japan ${ }^{2}$ Department of Biomedical Engineering, Iwate Medical University, 1-1-1 Idaidori, Yahaba-cho, Shiwa-gun, Iwate 028-3694, Japan

${ }^{3}$ Department of Prosthetic Dentistry, School of Dentistry, Ohu University, 31-1 Misumido, Tomitamachi, Koriyama, Fukushima 963-8611, Japan

${ }^{4}$ Department of Oral and Maxillofacial Implantology, Tokyo Dental College, 2-9-18 Kandamisaki-cho, Chiyoda-ku, Tokyo 101-0061, Japan

${ }^{5}$ Oral Health Science Center, Tokyo Dental College, 2-9-18 Kandamisaki-cho, Chiyoda-ku, Tokyo 101-0061, Japan

Corresponding author, Katsunori FURUYA; E-mail: kfuruya@tdc.ac.jp
\end{abstract}

\begin{abstract}
The objective of this study was to investigate the low temperature degradation characteristics of 2 types of high strength yttriastabilized tetragonal zirconia polycrystal (Y-TZP) in order to evaluate its suitability for implant body, implant superstructure or abutment. Disk-shaped conventional Y-TZP (0.25 mass\% alumina) subjected to hot isostatic press treatment (HIP-Y-TZP) and Y-TZP $/ 4 \mathrm{Al}_{2} \mathrm{O}_{3}$ with additional alumina (4.0 mass\%) were mirror-polished. Accelerated aging tests with $134^{\circ} \mathrm{C}$ for $5 \mathrm{~h}$ at $0.2 \mathrm{MPa}$ and $180^{\circ} \mathrm{C}$ for $5 \mathrm{~h}$ at $1.0 \mathrm{MPa}$ were performed using an autoclave. Biaxial flexural strength and crystal phases were evaluated. Strength decreased as the proportion of monoclinic phase increased after accelerated aging treatment for both types of high-strength Y-TZPs. Despite the low alumina content, HIP-Y-TZP showed higher static strength and strength after accelerated aging treatment compared to $\mathrm{Y}-\mathrm{TZP} / 4 \mathrm{Al}_{2} \mathrm{O}_{3}$. However, both types of Y-TZP had adequate strength to be used as dental restorations even after accelerated aging treatment, therefore, its clinical suitability was considered high.
\end{abstract}

Keywords: High strength Y-TZP, HIP treatment, Alumina content, Biaxial flexural strength, Crystal phase

\section{INTRODUCTION}

Currently in clinical dentistry, the extensive use of computer-aided design and computer-aided manufacturing (CAD/CAM) systems and the introduction of high strength ceramics, such as tetragonal zirconia polycrystal (TZP) and TZP-alumina composite materials, has allowed the use of all ceramic restorations to accommodate complicated cases involving bridges and connected restorations ${ }^{1-4)}$. In particular, TZP is used for implant materials including implant bodies, implant abutments, crowns, and bridge frameworks ${ }^{5}$.

The mechanical properties of TZP is known to degrade in the presence of high temperature and moisture due to low temperature degradation, which is caused by the crystal phase transformation from tetragonal to monoclinic phase ${ }^{6,7)}$. Some studies indicate that low temperature degradation does not occur near body temperature, however in the field of orthopedic surgery, approximately 400 artificial TZP femoral heads placed in 2001 were reported to have undergone damage due to low temperature degradation ${ }^{8.10)}$. In order to ensure the long-term success of TZP implant materials in the oral cavity, it is necessary to investigate the characteristics of low-temperature degradation in order to develop high strength TZPs with durability.

Hot isostatic pressing (HIP) and increased alumina content are some methods used to improve the strength of conventional $\mathrm{TZP}^{11,12)}$. HIP treatment under high pressure in an inert atmosphere leads to increased strength and translucency by significantly reducing internal voids ${ }^{12,13)}$. Iijima et al. reported that fatigue durability of conventional yttria-stabilized tetragonal zirconia polycrystals (Y-TZPs) was significantly improved by HIP treatment ${ }^{14)}$, and Koyama et al. reported that Y-TZP after HIP treatment possessed superior fatigue characteristics compared to grade 2 titanium $^{15}$.

A study reported that the addition of alumina improved strength and fracture toughness by reducing anisotropy in the monoclinic phase ${ }^{16)}$. Aluminatoughened zirconia (ATZ) and ceria-stabilized tetragonal zirconia polycrystals (Ce-TZP) $/ \mathrm{Al}_{2} \mathrm{O}_{3}$ (NanoZR) with alumina content of approximately 20 mass\% has been reported to have high strength and fatigue durability, and these materials are used to manufacture implant materials $^{17,18)}$. Takano et al. reported that the fatigue strength of NanoZR was more than twice as high as the standard fatigue strength of conventional TZP (320 MPa), as defined in ISO $13356^{19}$. However, TZP with high alumina content is not suitable for implant superstructure or abutments because translucency significantly declines along with the increase in hardness and Young's modulus ${ }^{20)}$.

ZirTough $\left(\mathrm{Y}-\mathrm{TZP} / 4 \mathrm{Al}_{2} \mathrm{O}_{3}\right)$ is Y-TZP with an alumina content of about 4.0 mass $\%$ with improved resistance to low temperature degradation ${ }^{21-23)}$. In addition, since the added amount of alumina is less than ATZ or NanoZR, the translucency, hardness and Young's modulus are relatively similar to conventional Y-TZP, therefore, its application on implant superstructure and abutments is more suitable than ATZ and NanoZR. Accordingly, high strength Y-TZP, Y-TZP treated with HIP (HIP- 
Y-TZP) and Y-TZP with 4.0 mass\% alumina content $\left(\mathrm{Y}-\mathrm{TZP} / 4 \mathrm{Al}_{2} \mathrm{O}_{3}\right)$ in this study, seems to be suitable for dental implants as well as fixed dental prostheses.

In order to use high strength Y-TZP in the oral cavity, in this study, it is necessary to investigate the characteristics of low temperature degradation, however, not many reports have done. Especially, no paper was found the mechanical properties evaluated by biaxial flexural testing instead of fracture toughness, and direct comparison between HIP-Y-TZP and Y-TZP $/ 4 \mathrm{Al}_{2} \mathrm{O}_{3}$. The objective of this study was to investigate low temperature degradation characteristics of 2 types of high-strength Y-TZP (HIP-Y-TZP and Y-TZP $/ 4 \mathrm{Al}_{2} \mathrm{O}_{3}$ ). The biaxial flexural strength of high-strength Y-TZP was determined by subjecting accelerated aging treatment. Phase transformation was also studied using X-ray diffractometry (XRD). In addition, Vickers hardness test and scanning electron microscope (SEM) observation were performed.

\section{MATERIALS AND METHODS}

\section{Preparation of TZP specimens}

In this study, 2 types of high-strength Y-TZP were used: Y-TZP treated with HIP (HIP-Y-TZP) and Y-TZP with additional alumina (Y-TZP/4 $/ \mathrm{Al}_{2} \mathrm{O}_{3}$, ZirTough) (Table 1). For HIP-Y-TZP specimens, Y-TZP powder (TZ-3YB-E, Tosoh, Tokyo, Japan) was sintered for $2 \mathrm{~h}$ at $1,350^{\circ} \mathrm{C}$ under atmospheric pressure, subsequently HIP treatment was performed at $1,300^{\circ} \mathrm{C}$ for $1 \mathrm{~h}$ in argon atmosphere (147 $\mathrm{MPa}$ ). For Y-TZP $/ 4 \mathrm{Al}_{2} \mathrm{O}_{3}$ specimens, Y-TZP (ZirTough, Kuraray Noritake Dental, Miyoshi, Aichi, Japan) with alumina content of about 4.0 mass $\%$ was fired at $1,500^{\circ} \mathrm{C}$ for $2 \mathrm{~h}$ under atmospheric pressure.

Each high-strength Y-TZP specimen was sectioned using a diamond disk to form a disk shape. Both sides of the disk were mirror-polished by a polishing apparatus (Ecomet 250 and Automet 250, Buehler, Lake Bluff, IL, USA) using 9 and $3 \mu \mathrm{m}$ diamond particles and colloidal silica of $0.02 \mu \mathrm{m}$. The specimens were subjected to ultrasonic cleaning for $10 \mathrm{~min}$ with acetone and ethanol then stored in dry atmosphere. The mean roughness $(\mathrm{Ra})$ of the mirror polished surface was less than $0.1 \mu \mathrm{m}$.

\section{Accelerated aging treatment}

Accelerated aging treatment was performed using an autoclave (Table 2). Accelerated aging treatment consisted of 2 conditions: $134^{\circ} \mathrm{C}$ for $5 \mathrm{~h}$ at $0.2 \mathrm{MPa}$ $(\mathrm{HT} 134)^{24)}$ and $180^{\circ} \mathrm{C}$ for $5 \mathrm{~h}$ at $1.0 \mathrm{MPa}(\mathrm{HT} 180)^{25,26)}$. For HT134, an autoclave (HICLAVE HG-50, Hirayama, Kasukabe, Japan) was used for accelerated aging treatment. For HT180, specimens were immersed in 20 $\mathrm{mL}$ of distilled water in a hydrothermal vessel (Shikoku Rika., Kochi, Japan), which consisted of a Teflon ${ }^{\circledR}$ inner vessel and a stainless steel jacket. The vessel was kept at $180^{\circ} \mathrm{C}$ for $5 \mathrm{~h}$ in an electric furnace (KDF90, Denken Highdental, Tokyo, Japan). After the treatment, the specimens were washed with distilled water and dried at $60^{\circ} \mathrm{C}$ for $24 \mathrm{~h}$. As the control, specimens not subjected to accelerated aging treatment (as-polished) were used.

\section{Flexural strength test}

Flexural strength was evaluated through the biaxial flexural test by modifying method of the ISO6872 27,28$)$. Using a universal testing machine (Autograph AG-I $20 \mathrm{kN}$, Shimadzu, Kyoto, Japan), flexural test was conducted at a crosshead speed of $0.5 \mathrm{~mm} / \mathrm{min}$ in air at room temperature. Disk specimens having a thickness of $0.5 \mathrm{~mm}$ and diameter of $13 \mathrm{~mm}$ were placed on 3 steel spheres positioned 120 degrees apart in a circle $(8.0 \mathrm{~mm}$ in diameter). A flat-end loading cylinder with a radius of $0.8 \mathrm{~mm}$ was then applied. Biaxial flexural strength was calculated using the equation listed in ISO6872, with a Poisson's ratio value of 0.25 for each specimen. Six specimens from each group were used under each experimental condition.

Flexural strength distributions were estimated based on Weibull distributions, which were calculated

Table 1 High-strength Y-TZP used in this study

\begin{tabular}{cccc}
\hline Sample code & Product name & \multicolumn{1}{c}{ Composition (mass\%) } & Manufacturer \\
\hline HIP-Y-TZP & TZ-3YB-E & $\mathrm{ZrO}_{2}:$ balanced, $\mathrm{Y}_{2} \mathrm{O}_{3}: 5.16, \mathrm{Al}_{2} \mathrm{O}_{3}: 0.25$, & Tosoh, Tokyo, Japan \\
& $\mathrm{Na}_{2} \mathrm{O}: 0.021, \mathrm{SiO}_{2}: 0.007, \mathrm{Fe}_{2} \mathrm{O}_{3}: 0.003$ & Kuraray Noritake Dental, \\
Y-TZP/4Al $\mathrm{O}_{3}$ & ZirTough & $\mathrm{ZrO}_{2}:$ balanced, $\mathrm{Y}_{2} \mathrm{O}_{3}: 4.5, \mathrm{Al}_{2} \mathrm{O}_{3}: 4.0$, & Miyoshi, Aichi, Japan \\
\hline
\end{tabular}

HIP: hot isostatic pressing, Composition is based on manufacturer's information.

Table 2 Condition for accelerated aging treatment

\begin{tabular}{lccc}
\hline Condition & Temperature $\left({ }^{\circ} \mathrm{C}\right)$ & Pressure $(\mathrm{MPa})$ & Duration time $(\mathrm{h})$ \\
\hline as-polished & Room temp. & Atmospheric pressure & - \\
HT134 & 134 & 0.2 & 5 \\
HT180 & 180 & 1.0 & 5 \\
\hline
\end{tabular}


using the following equation:

$$
\left.P(\sigma)=1-\exp \left[-\sigma / \sigma_{n 0}\right)^{m}\right]
$$

where, $P(\sigma)=$ fracture probability defined by the relation $P(\sigma)=i /(N+1), i=$ rank of strength, $N=$ total number of specimens, $\sigma=$ strength at given $P(\sigma), \sigma_{n 0}=$ characteristic strength, $m=$ Weibull modulus.

\section{Vickers hardness test}

Vickers hardness number (Hv) was obtained using a Vickers hardness tester (Micro Hardness Tester, Shimadzu) with a load of $9.8 \mathrm{~N}$ and a loading time of 20 s. Four specimens were tested per condition. Four specimens from each group were used under each experimental condition.

\section{SEM observation}

In order to observe the surface of high-strength Y-TZP, thermal etching was performed at $1,350^{\circ} \mathrm{C}$ for $20 \mathrm{~min}$ in atmosphere pressure using an as-polished sample. Then carbon coating was performed and the surface of each sample was observed using a SEM (SU6600, Hitachi, Hitachi, Japan).

Specimens subjected to accelerated aging treatments and fracture tests were also observed after ultrasonic cleaning with ethanol and distilled water for 5 min and carbon coating.

\section{$X R D$ analysis}

XRD analysis was carried out on the surface of the specimens subjected to accelerated aging treatment using the $\theta-2 \theta$ method (analysis depth: 6-10 $\mu \mathrm{m}$ ) and the thin film method (analysis depth: approximately $0.5 \mu \mathrm{m})$. The $\theta-2 \theta$ method was a multipurpose X-ray diffractometer (Ultima IV, Rigaku, Tokyo, Japan), and the test conditions were X-ray output: CuKa, $40 \mathrm{kV}, 40$ $\mathrm{mA}$, and scan speed: $5 \% \mathrm{~min}$. For the thin film method, a thin film X-ray diffractometer (Smart Lab, Rigaku) was used. Measuring conditions were X-ray output: $\mathrm{CuK} \alpha$, $40 \mathrm{kV}, 30 \mathrm{~mA}, 1^{\circ}$ incident angle, using step scan: $0.02^{\circ}$ for $2 \mathrm{~s}$ fixed.

The analysis depth (t) on the mirror-polished specimens was calculated by the following equation ${ }^{29,30)}$.

$$
\mathrm{t}=(K x / 2 \mu) \sin \theta
$$

where, $\mu$ (X-ray adsorption coefficient) for $3 \mathrm{Y}-\mathrm{TZP}=0.0653$ $\mu \mathrm{m}^{-1}, K x=-\ln (0.01)=4.605$ on the assumption that X-ray diffraction intensity is detected to $99 \%$ during $2 \theta=26-34^{\circ}$ for monoclinic and tetragonal phase of zirconia.

The relative amount of monoclinic to tetragonal phase was calculated based on the method of Garvie and Nicholson's method ${ }^{31}$. Three specimens were analyzed for each condition.

\section{Statistical analysis}

Two-way analysis of variance (ANOVA) was performed on the biaxial bending strength and Vickers hardness using material type and aging conditions as factors. In addition, Tukey's multiple comparison test was performed after carrying out one-way ANOVA for each material and aging condition. The significance level was set to $\alpha=0.05$.

\section{RESULTS}

\section{Flexural strength and Weibull distribution}

As a result of 2-way ANOVA, significant differences were observed in biaxial flexural strength when both material and aging conditions were considered (Table 3). Figure 1 displays the biaxial flexural strength of specimens. For HIP-Y-TZP, the flexural strength of as-polished, HT134, and HT180 were $1,881 \pm 172,1,730 \pm 166$, and $1,513 \pm 244 \mathrm{MPa}$, respectively. For $\mathrm{Y}-\mathrm{TZP} / 4 \mathrm{Al}_{2} \mathrm{O}_{3}$, the flexural strength of as-polished, HT134, and HT180 were $1,546 \pm 101,1,414 \pm 93$, and $1,275 \pm 112 \mathrm{MPa}$, respectively. HIP-Y-TZP showed greater flexural strength than $\mathrm{Y}-\mathrm{TZP} / 4 \mathrm{Al}_{2} \mathrm{O}_{3}$ under all treatment conditions. In regards to aging conditions, HIP-Y-TZP showed a

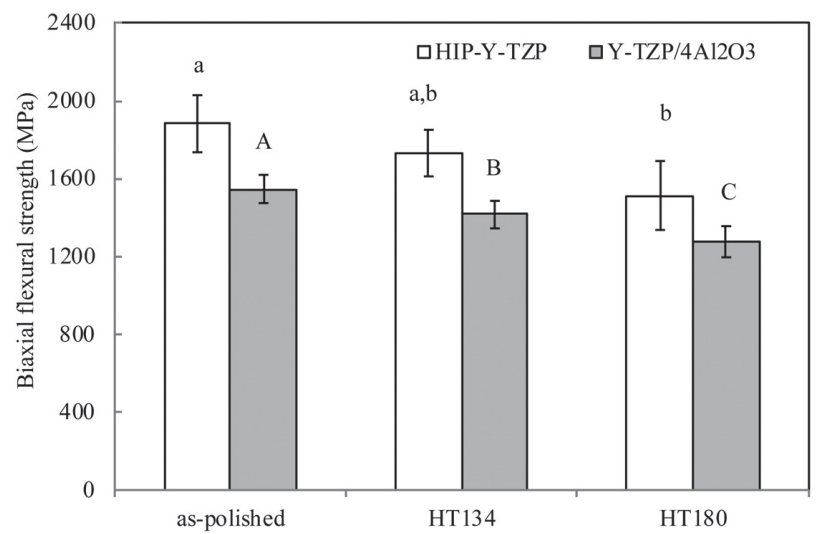

Fig. 1 Biaxial flexural strength of as-polished and accelerated aging-treated specimens.

Different letters indicate significant differences on each specimen $(p<0.05)$.

Table 3 Results of 2-way ANOVA for biaxial flexural strength

\begin{tabular}{ccccccc}
\hline Factor & Sum of squares & df & Mean square & F & $p$ & $<0.01$ \\
Material & $616,361.9$ & 1 & $308,181.0$ & 22.1 & & $<*$ \\
Treatment & $789,737.3$ & 2 & $789,737.3$ & 56.6 & $<0.01$ \\
Interaction & $15,915.2$ & 2 & $7,957.6$ & 0.6 & 0.57 \\
\hline
\end{tabular}


decrease in strength in the order of HT134 and HT180 as accelerated aging treatment temperature increased when compared with as-polished; a significant difference was indicated between as-polished and HT180 $(p<0.05)$. For Y-TZP $/ 4 \mathrm{Al}_{2} \mathrm{O}_{3}$, the strength decreased as the temperature of accelerated aging treatment increased, and a significant difference was observed between aspolished and HT134, HT134 and HT180, and as-polished and HT180 $(p<0.05)$.

Figure 2 shows the Weibull distributions of HIP-YTZP and Y-TZP $/ 4 \mathrm{Al}_{2} \mathrm{O}_{3}$ for as-polished and accelerated aging treatment (HT134, HT180). In HIP-Y-TZP, the Weibull modulus (m) of H180 specimens was decreased compared to as-polished and HT134 specimen. In Y-TZP $/ 4 \mathrm{Al}_{2} \mathrm{O}_{3}$, the Weibull modulus (m) of HT134 and HT180 specimens were decreased compared to aspolished specimens.

Vickers hardness

Results of the Vickers hardness test are shown in Fig. 3 . As a result of 2 -way ANOVA, significant differences were found only between materials, and no difference was indicated between treatment conditions (Table 4). Under all treatment conditions, $\mathrm{Hv}$ of HIP-Y-TZP and Y-TZP/4 $/ \mathrm{Al}_{2} \mathrm{O}_{3}$ were $1,350-1,400$ and 1,250-1,300, respectively.

\section{SEM observation}

A typical SEM with secondary electron image of a specimen subjected to thermal etching on as-polished specimen is shown in Fig. 4. HIP-Y-TZP exhibited a surface in which fine crystal grains of equal size were evenly dispersed and almost no voids (\#) were observed. On the contrary, Y-TZP $/ 4 \mathrm{Al}_{2} \mathrm{O}_{3}$ observed to have crystal grains of various grain sizes in addition to voids (\#) and

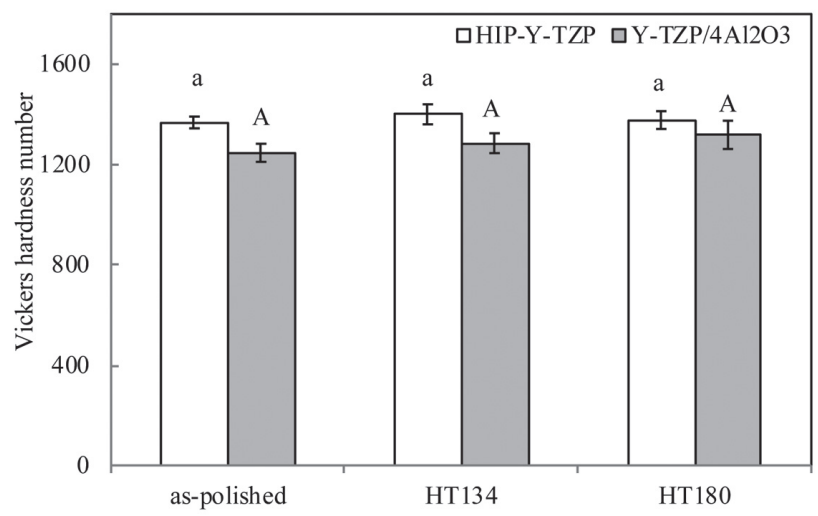

Fig. 3 Vickers hardness number of as-polished and accelerated aging-treated specimens.

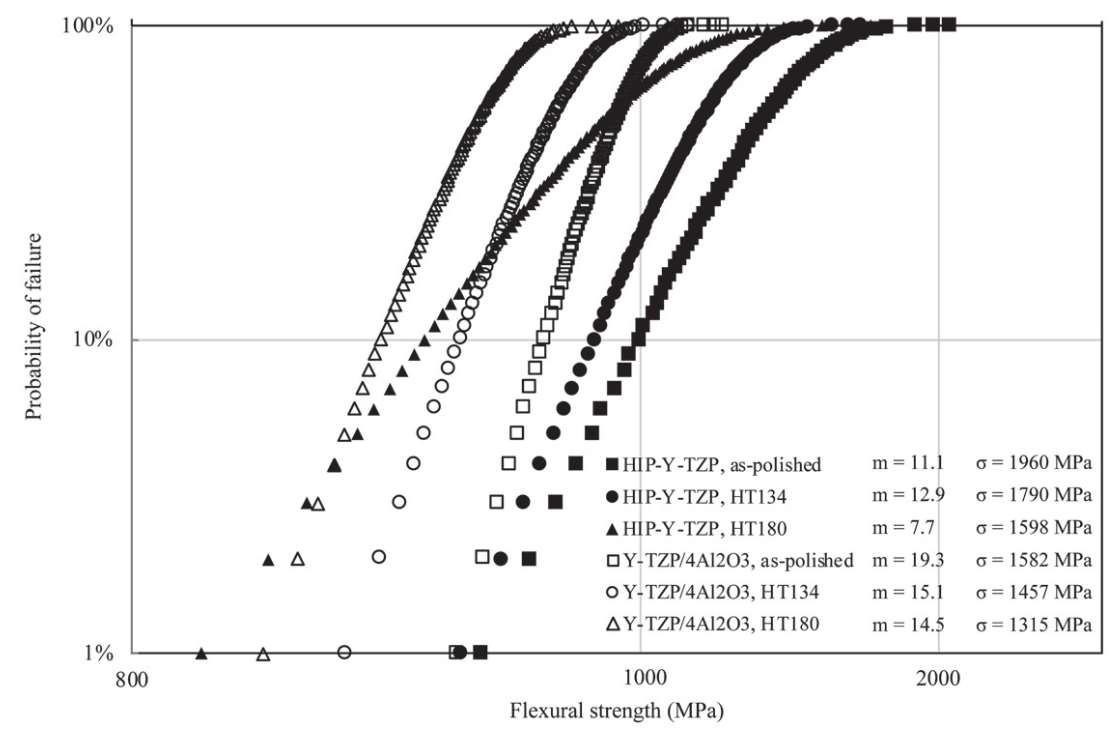

Fig. 2 Cumulative Weibull distribution of HIP-Y-TZP and Y-TZP/4 $4 \mathrm{Al}_{2} \mathrm{O}_{3}$ for as-polished and accelerated aging treatment (H134, H180). $\mathrm{m}$ : Weibull modulus, $\sigma$ : Weibull characteristic strength

Table 4 Results of 2-way ANOVA for Vickers hardness number

\begin{tabular}{ccccccc}
\hline Factor & Sum of squares & df & Mean square & F & $p$ & $* *$ \\
Material & $789,737.3$ & 1 & $789,737.3$ & 37.0 & 2.5 & 0.11 \\
Treatment & $7,780.8$ & 2 & $58,136.9$ & $2,339.9$ & 1.5 & 0.25 \\
Interaction & $4,679.9$ & 2 & 25 & \\
\hline
\end{tabular}


particles assumed to be alumina $\left({ }^{*}\right)$ caused by low average atomic number of alumina compared to zirconia.

SEM images of the surface of as-polished and accelerated aging-treated specimens (without thermal etching) are shown in Fig. 5 (Upper: low magnification, Lower: high magnification). Changes in surface morphologies due to accelerated aging treatment were not observed in both materials. In HIP-Y-TZP, surfaces appeared smooth and homogeneous were and under all conditions. In Y-TZP $/ 4 \mathrm{Al}_{2} \mathrm{O}_{3}$, black precipitates, which assumed to be alumina particles, were observed on the surface for all conditions.

Figure 6 shows a typical SEM image of the fracture surface after the flexural test of the sample subjected to accelerated aging treatment (HT180). Apparent deterioration layer was not observed on the surface
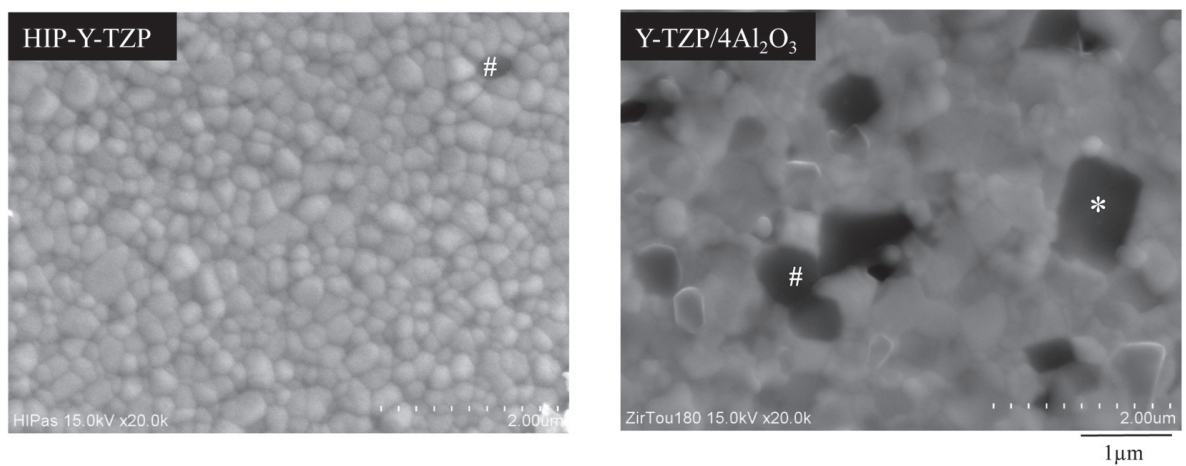

Fig. 4 Representative SEM images of as-polished high-strength Y-TZP with thermal etching.

\#: micro defect, ${ }^{*}$ :alumina particle

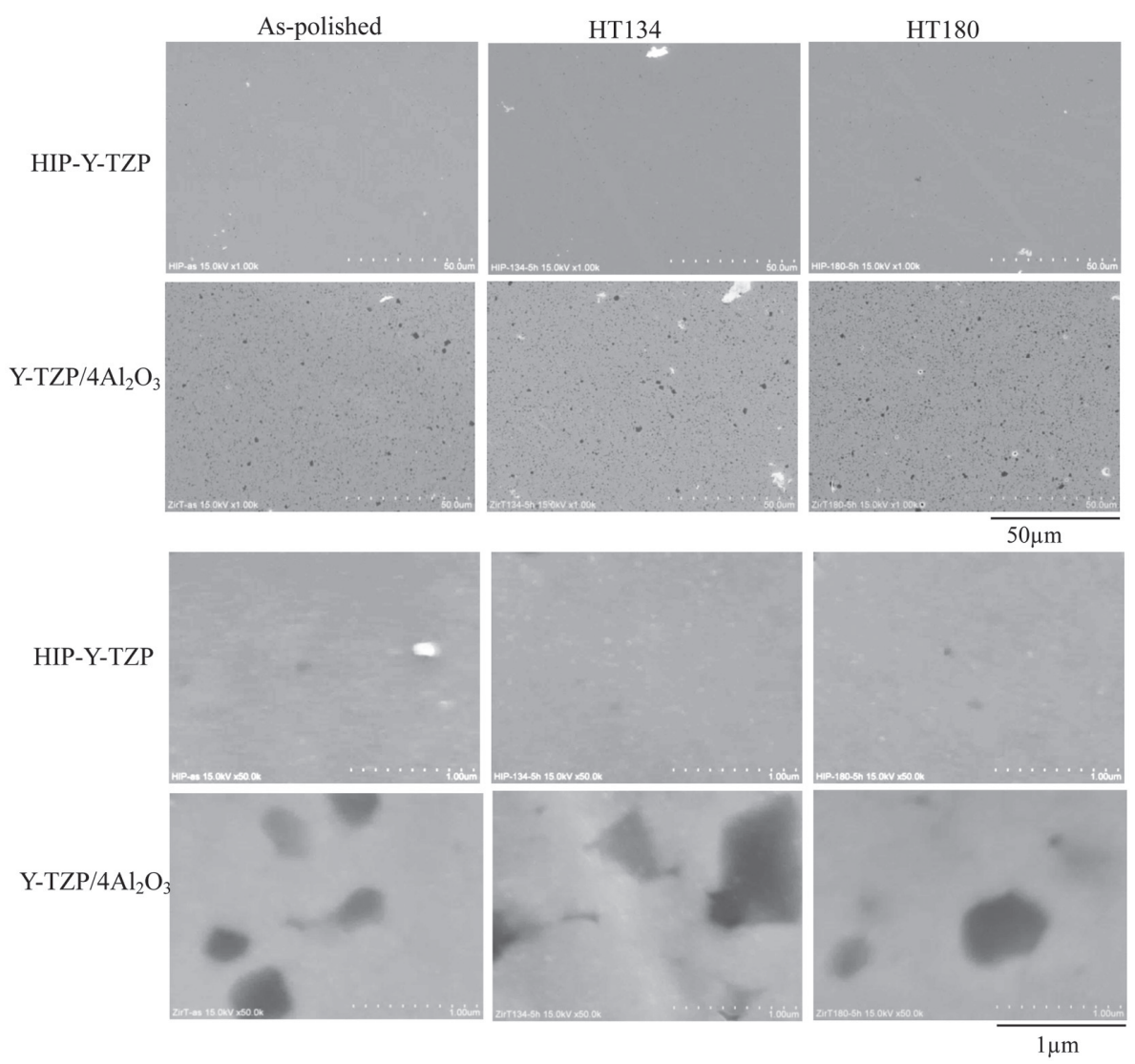

Fig. 5 SEM images of as-polished and accelerated aging-treated specimens without thermal etching.

Upper: low magnification, Lower: high magnification 
layer of any of the samples by the SEM observation that seemed to be very thin layer.
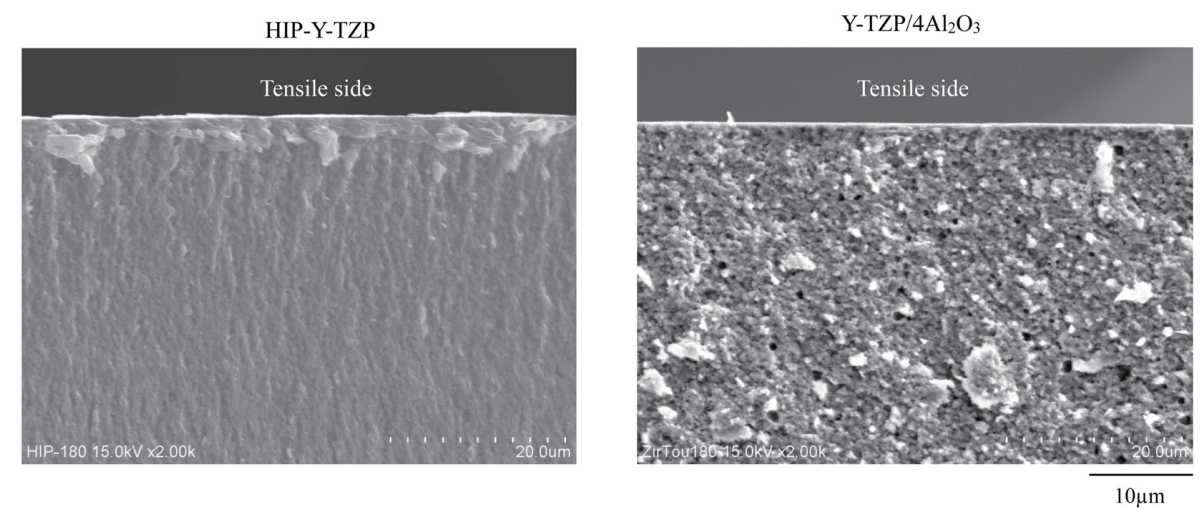

Fig. 6 Representative SEM images of fracture surface of high-strength Y-TZP with accelerated aging treatment (HT180).

\section{XRD analysis}

Figures 7 and 8 show representative XRD profiles of HIP-Y-TZP and Y-TZP $/ 4 \mathrm{Al}_{2} \mathrm{O}_{3}$ using the $\theta-2 \theta$ and thin film method, respectively. In the $\theta-2 \theta$ method (Fig. 7,

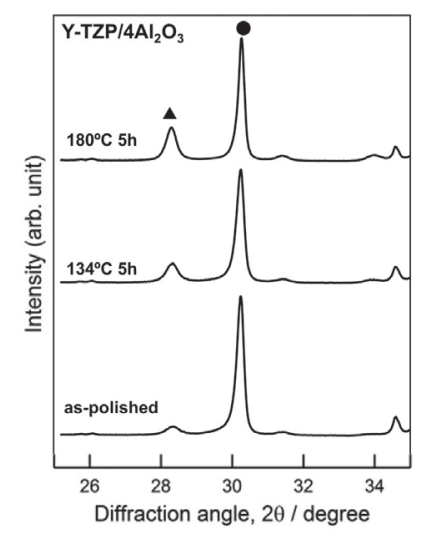

Fig. 7 Representative XRD patterns of as-polished and accelerated aging-treated specimens under $\theta-2 \theta$ method (depth of analysis: 6-10 $\mu \mathrm{m}$ ).

$\bullet$ : tetragonal, $\boldsymbol{\Delta}$ : monoclinic

a)

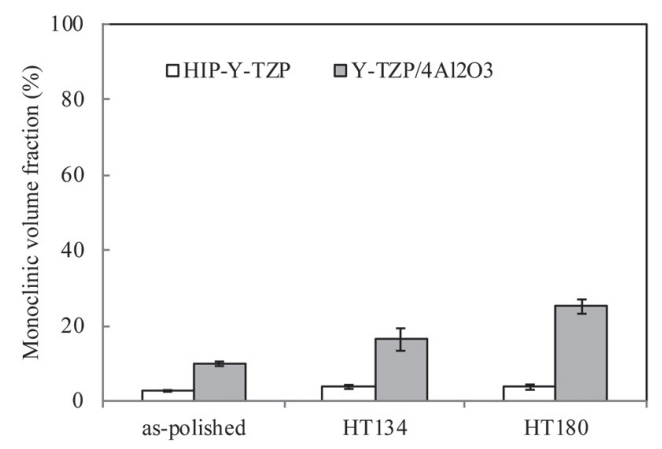

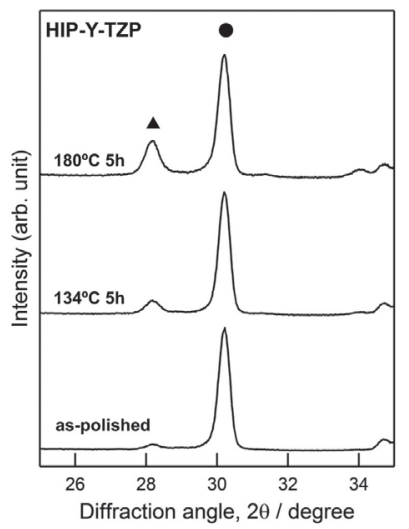

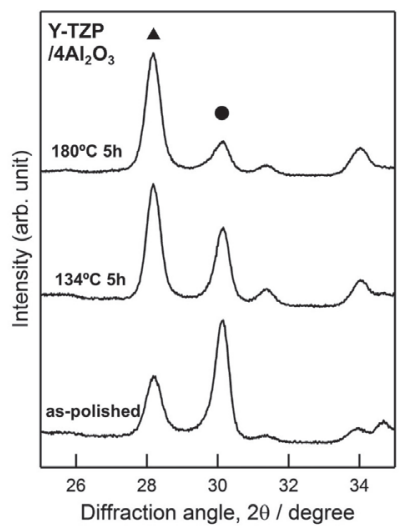

Fig. 8 Representative XRD patterns of as-polished and accelerated aging-treated specimens under thin film method (Approximate analysis depth: $0.5 \mu \mathrm{m}$ ).

$\bullet$ : tetragonal, $\boldsymbol{\Delta}$ : monoclinic

b)

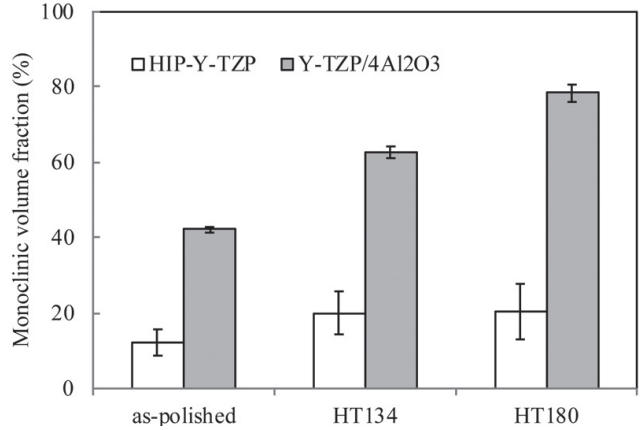

Fig. 9 Monoclinic zirconia $\left(\mathrm{m}-\mathrm{ZrO}_{2}\right)$ volume fraction (\%) of as-polished and accelerated agingtreated specimens.

a) $\theta-2 \theta$ method (analysis depth: $6-10 \mu \mathrm{m}$ ), b) Thin film method (approximate analysis depth: $0.5 \mu \mathrm{m}$ ) 
depth of analysis: 6-10 $\mu \mathrm{m})$, HIP-Y-TZP showed mostly tetragonal peaks; monoclinic peaks were confirmed only in small amounts. In Y-TZP $/ 4 \mathrm{Al}_{2} \mathrm{O}_{3}$, monoclinic phase was observed in small amounts in as-polished in addition to tetragonal phase, and monoclinic peaks increased with HT134 and HT180 as the temperature of accelerated aging treatment increased.

In the thin film method (Fig. 8, depth of analysis: about $0.5 \mu \mathrm{m}$ ), the monoclinic phase peak was greater compared to the $\theta-2 \theta$ method. In HIP-Y-TZP, monoclinic phase was slightly observed in as-polished, and as the temperature of accelerated aging treatment increased, monoclinic peak increased. On the other hand, in $\mathrm{Y}-\mathrm{TZP} / 4 \mathrm{Al}_{2} \mathrm{O}_{3}$, a considerable amount of monoclinic phase was already observed in the as-polished state, and the increase in the peak of the monoclinic phase and the decrease in the peak of the tetragonal phase.

The monoclinic content calculated from the X-ray diffraction analyses is shown in Fig. 9. In the $\theta-2 \theta$ method for HT180, the proportion of monoclinic phase was less than $4 \%$ for HIP-Y-TZP after treatment, whereas this proportion was $25 \%$ for $\mathrm{Y}-\mathrm{TZP} / 4 \mathrm{Al}_{2} \mathrm{O}_{3}$. In the thin film method, the proportion of monoclinic phase was approximately $20 \%$ for HIP-Y-TZP after accelerated aging treatment of $\mathrm{HT} 180$. For $\mathrm{Y}-\mathrm{TZP} / 4 \mathrm{Al}_{2} \mathrm{O}_{3}$, the proportion of monoclinic phase was $40 \%$ or more before accelerated aging treatment and $80 \%$ after accelerated aging treatment of HT180.

\section{DISCUSSION}

This study aimed to clarify the low-temperature degradation characteristics of 2 types of high-strength Y-TZPs by subjecting specimens to accelerated aging treatment. The biaxial flexural strength, Vickers hardness, surface observation, and X-ray diffraction characteristics were examined to compare the influence of accelerated aging treatment among materials.

The thickness of each specimen was established as $0.5 \mathrm{~mm}$ in this study. This was because the minimum thickness of TZP prosthesis is approximately $0.5 \mathrm{~mm}$ and a report suggested that the influence of low temperature degradation increases as thickness decreases ${ }^{32}$. The TZP specimens used in this study were mirror polished. Surface roughness is known to affect the mechanical properties of TZP, therefore an investigation using a roughened surface would be ideal when its application for use as implant materials is considered. However, in order to clarify the low-temperature degradation characteristics of high-strength Y-TZP, it is necessary to investigate surface changes after accelerated aging treatment, therefore mirror polished specimens were used so that changes in surface properties could be easily examined. The characteristics of low temperature degradation on specimens with different surface roughness will be investigated in the future.

In this study, 2 conditions were used for accelerated aging treatment to compare the effects of low temperature degradation. The first condition was done according to the accelerated aging test regulated by
ISO $13356^{24)}$. However, ISO13356 is a standard used for implants in the orthopedic surgical field, therefore the environment in the oral cavity is not considered. In relation to this ISO standard, Chevalier et al. calculated the longevity of TZP from the proportion of monoclinic phase and reported that $134^{\circ} \mathrm{C} / 5 \mathrm{~h} / 0.2 \mathrm{MPa}$ corresponds to 15 to 20 years in $37^{\circ} \mathrm{C}$ water ${ }^{8,9)}$. This report stated that the proportion of monoclinic phase was $20 \%$ in 25 years, however, no decrease in strength was indicated. Unlike implants placed in orthopedic fields, dental implants are subjected to harsher conditions in the oral cavity including occlusion, mastication, temperature $/ \mathrm{pH}$ changes, and oral bacteria, therefore it was necessary to set conditions which were more severe than $134^{\circ} \mathrm{C} / 5 \mathrm{~h} / 0.2$ $\mathrm{MPa}$. A second condition, $180^{\circ} \mathrm{C} / 5 \mathrm{~h} / 1.0 \mathrm{MPa}$, was used in this study. This is used during the industrial ceramic durability test standardized by ISO10545-11 for ceramic tiles $^{25)}$ and JISA5207 for sanitary ware ${ }^{26)}$. The duration time for this standard is usually $1 \mathrm{~h}$, however, duration time was set to be the same as the first condition at $5 \mathrm{~h}$. If the strength was not reduced under this condition, it can be assumed that this material can function in the oral cavity for long periods of time.

The biaxial flexural test was conducted by modifying method of the ISO6872 in this study. As general flexural test methods, there are the 3-point and 4-point flexural test, however there is a disadvantage that it is difficult to remove the edges of the specimens which significantly affects strength. For this reason, biaxial flexural test is often used to interpret fracture properties of ceramic materials. The biaxial flexural test has also been adopted by the American Society for Testing and Materials to measure the strength of brittle materials such as ceramics, and it is also an international standard for dental ceramics. The biaxial flexural test considers the disadvantage of edge fracture to enable more accurate measurements of strength to be made ${ }^{33}$. Furthermore, the biaxial flexural strength was measured using the $0.5 \mathrm{~mm}$ thickness specimen in this study, despite the thickness of the specimen was specified as $1.2 \pm 0.2 \mathrm{~mm}$ in ISO6872. This reason was as follows; 1) zirconia restorations with minimum thickness have been growing in clinical situation due to extremely high strength of zirconia, and thus 2) the $0.5 \mathrm{~mm}$ thickness specimens were used in previous study ${ }^{14,19)}$, and it was reported that the thickness of the specimen had less effect on the failure distribution and increase in thickness had little effect on flexural strength of the material ${ }^{34-366}$.

Fracture toughness by methods relying on indentation crack lengths with Vickers indentations was not evaluated in this study. The main reason for this was because the correlation was small between the fracture toughness value and the fatigue strength reported in literature in past dynamic fatigue tests ${ }^{4,14,15,19)}$. Therefore, it was necessary to evaluate the dynamic fatigue strength as specified in ISO14801 instead of fracture toughness to determine long term material durability in the oral cavity $^{37}$. In this study, the load value of $9.8 \mathrm{~N}$ was used for Vickers hardness test; this did not correspond to the recommended load of $294 \mathrm{~N}$ for fracture toughness test ${ }^{21}$. 
The reason for this was because the inner hardness of specimens is reflected when a large load is applied but this is not suitable when measuring the transformation layer on the TZP surface layer where the influence of low temperature degradation is observed. The load of $294 \mathrm{~N}$ was used due to the concern that specimens with 0.5 $\mathrm{mm}$ thickness would fracture during the hardness test. Since the penetration depth of the Vickers test under the conditions in this study was about $7 \mu \mathrm{m}$, it was assumed that the surface transformation layer did not affect the material hardness.

In this study, the flexural strength before accelerated aging treatment (as-polished) for HIP-Y-TZP and $\mathrm{Y}-\mathrm{TZP} / 4 \mathrm{Al}_{2} \mathrm{O}_{3}$ was $1,881 \pm 172$ and $1,546 \pm 101 \mathrm{MPa}$, respectively; these values are greater than the flexural strength of conventional Y-TZP which is approximately $1,000 \mathrm{MPa}^{38)}$. Reports have indicated that the strength of HIP-Y-TZP was about twice the amount of conventional Y-TZP because the degree of voids is reduced after HIP treatment ${ }^{14)}$. Y-TZP $/ 4 \mathrm{Al}_{2} \mathrm{O}_{3}$, on the other hand, possess greater strength due to increased compressive residual stress from the increased amount of alumina added ${ }^{39)}$. These results are consistent with a study done by Swain, which reported that volume expansion due to phase transformation from tetragonal to monoclinic phase increases compressive residual stress and improves strength $^{40)}$. Inokoshi et al. compared $\mathrm{Y}-\mathrm{TZP} / 4 \mathrm{Al}_{2} \mathrm{O}_{3}$ and Y-TZP with a small addition of alumina and reported that the proportion of monoclinic phase were equal after firing alone, whereas when polished with diamond suspension, the proportion of monoclinic phase increased significantly in $\mathrm{Y}-\mathrm{TZP} / 4 \mathrm{Al}_{2} \mathrm{O}_{3}$. This study concluded that compressive residual stress accumulates and strengthens Y-TZP as the monoclinic phase increases on the surface ${ }^{22,23,41)}$. In this current study, more than $40 \%$ monoclinic phase was observed on the surface layer of as-polished in $\mathrm{Y}-\mathrm{TZP} / 4 \mathrm{Al}_{2} \mathrm{O}_{3}$. Therefore, it was assumed that $\mathrm{Y}-\mathrm{TZP} / 4 \mathrm{Al}_{2} \mathrm{O}_{3}$ had greater monoclinic phase after mirror polishing leading to increased compressive residual stress and improved strength. In addition, Y-TZP $/ 4 \mathrm{Al}_{2} \mathrm{O}_{3}$ with about 4 mass\% alumina possessed inferior in strength compared to ATZ of Y-TZP type with about 20 mass\% alumina, but was similar to the strength of Ce-TZP type NanoZR. Accordingly, it is assumed that the increase in elastic modulus and decrease in the translucency which accompany the increase in alumina content were reduced.

As a result of the flexural test after accelerated aging treatment, both HIP-Y-TZP and Y-TZP $/ 4 \mathrm{Al}_{2} \mathrm{O}_{3}$, strength decreased in the order of HT134 and HT180 as the temperature of accelerated aging treatment increased. This result was consistent with the report of other accelerated aging tests including a study done by Flinn et al. which reported that flexural strength decreased after subjecting to accelerated aging treatment at 134 and $180^{\circ} \mathrm{C}^{22,41)}$. Low temperature degradation of TZP occurs due to a phase transformation from tetragonal to monoclinic on the surface, causing the surface to swell and crack eventually leading to hydrolysis. Therefore, the greater the transition rate from tetragonal to

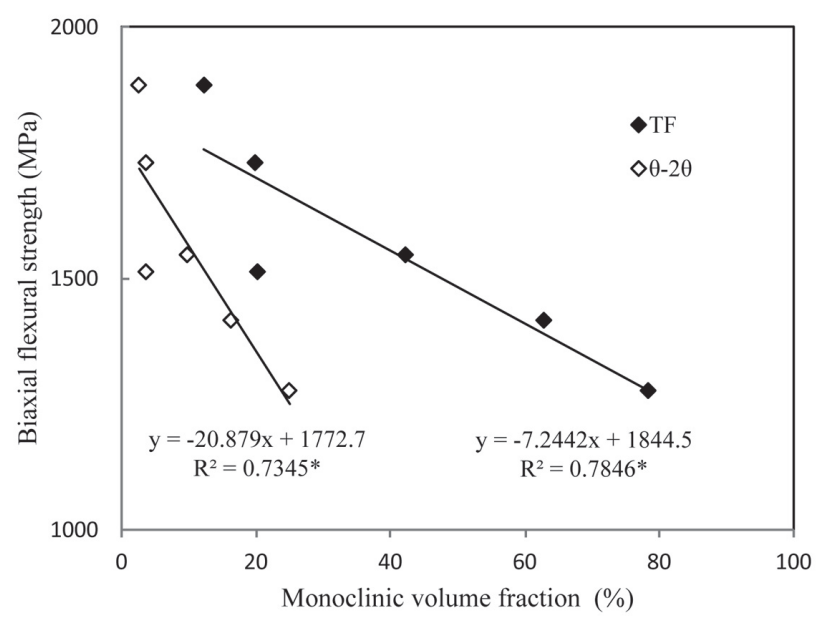

Fig. 10 Relationship between biaxial flexural strength and monoclinic volume fraction for $\theta-2 \theta$ method $(\theta-2 \theta)$ and thin film method (TF).

monoclinic phase on the surface, the more likely that low temperature degradation will occur.

From the X-ray diffraction analysis, HIP-Y-TZP showed a large proportion of tetragonal in as-polished specimens and an increased peak of monoclinic phase after accelerated aging treatment. On the other hand, in $\mathrm{Y}-\mathrm{TZP} / 4 \mathrm{Al}_{2} \mathrm{O}_{3}$, the proportion of monoclinic crystals was more than $40 \%$ in as-polished specimens, which increased to approximately $80 \%$ after accelerated aging treatment at $180^{\circ} \mathrm{C}$ for $5 \mathrm{~h}$. Therefore, it was confirmed that the proportion of monoclinic phase increased in both HIP-Y-TZP and Y-TZP $/ 4 \mathrm{Al}_{2} \mathrm{O}_{3}$ as the condition of treatment became severe. These results are consistent with the report by Flinn et al. that flexural strength decreases with the increase in monoclinic phase. It is also supported by the scatter plot graph of strength $v s$. monoclinic phase fraction that showed high relationship between biaxial flexural strength and monoclinic volume fraction (Fig. 10). It can be assumed that volume expansion occurred on the surface of the TZP due to accelerated aging treatment, which formed microcracks where moisture entered and resulted in decreased flexural strength due to hydrolysis. In addition, since the increase in proportion of monoclinic phase was significant in the thin film method ( $0.5 \mu \mathrm{m}$ from surface), it is apparent that accelerated aging treatment affects only the surface layer of TZP.

This was also supported by the fact that no change in hardness was observed after accelerated aging treatment. In addition, apparent deterioration layer was not observed on the surface layer of any of the samples by the SEM observation (HT180, Fig. 6). Accordingly, deterioration phenomena were evaluated by XRD analysis with thin film method as above mentioned.

On the contrary, a study reported that compressive residual stress on the surface in fact, increases when the proportion of monoclinic phase is high, which improves low temperature degradation ${ }^{39)}$. Furthermore, 
Munoz-Tabares and Anglada reported that the 10-20 $\mathrm{nm}$ microcrystalline layer present under the surface of polished zirconia was a transition layer from tetragonal to monoclinic phase, and this layer, along with residual compressive stress, is reported to play an important role for low temperature degradation resistance ${ }^{42}$.

As described above, phase transformation to monoclinic phase can be influenced by both reduction in strength by hydrolysis and improvement in strength by compressive residual stress, and the dominant cause cannot be unconditionally determined.

\section{Clinical implication}

As a result, both types of high-strength Y-TZP decreased in strength as a result of accelerated aging treatment due to increase in proportion of monoclinic phase. In addition, decrease of Weibull modulus $(\mathrm{m})$ in the severe condition of $180^{\circ} \mathrm{C}$ for $5 \mathrm{~h}(1.0 \mathrm{MPa})$ is remarkable in HIP-Y-TZP compared to Y-TZP $/ 4 \mathrm{Al}_{2} \mathrm{O}_{3}$, indicating that HIP-Y-TZP is prone to be subjected with low temperature degradation compared to Y-TZP $/ 4 \mathrm{Al}_{2} \mathrm{O}_{3}$. However, even in the severe condition of $180^{\circ} \mathrm{C}$ for $5 \mathrm{~h}(1.0 \mathrm{MPa})$, the strength for HIP-Y-TZP and Y-TZP/4Al $\mathrm{O}_{2}$ were $1,513 \mathrm{MPa}(19.6 \%$ reduction compared to as-polished) and 1,275 $\mathrm{MPa}$ (17.5\% reduction compared to as-polished), respectively. In contrast to conventional Y-TZP, where some of the same products could have up to $40 \%$ lower strength under the similar conditions, the strength reduction of high-strength Y-TZP used in this study was minimal compared to conventional Y-TZP ${ }^{22}$. It can be assumed that high strength was due to internal defects being reduced by HIP treatment for HIP-Y-TZP, and increase in alumina content for Y-TZP/4 $/ \mathrm{Al}_{2} \mathrm{O}_{3}{ }^{16)}$. By substituting these values into the equation to obtain the biaxial flexural strength, then calculating the fracture load at $1 \mathrm{~mm}$ thickness from the obtained flexural strength, fracture loads for HIP-Y-TZP and Y-TZP $/ 4 \mathrm{Al}_{2} \mathrm{O}_{3}$ were 895 and $756 \mathrm{~N}$, respectively. The occlusal force is reported to be approximately $250-400 \mathrm{~N}$ in the molar region and $140-170 \mathrm{~N}$ in the anterior region ${ }^{43)}$, and maximum biting forces is reported to be approximately $700 \mathrm{~N}^{44)}$, indicating that both types of high-strength Y-TZP could withstand occlusal forces in the oral cavity.

Among the materials used, HIP-Y-TZP was demonstrated to have higher strength than $\mathrm{Y}-\mathrm{TZP} / 4 \mathrm{Al}_{2} \mathrm{O}_{3}$ when subjected to accelerated aging treatment. This material is suitable for use as implant bodies, in addition to anterior prosthesis, because high translucency and sufficient elastic modulus is maintained due to its low alumina content.

\section{CONCLUSIONS}

1. Strength decreased as the proportion of monoclinic phase increased after accelerated aging treatment for both types of high-strength Y-TZP (HIP-YTZP, Y-TZP $/ 4 \mathrm{Al}_{2} \mathrm{O}_{3}$ ).

2. Despite low alumina content, HIP-Y-TZP had higher static strength and strength after accelerated aging treatment compared to
Y-TZP $/ 4 \mathrm{Al}_{2} \mathrm{O}_{3}$.

3. Both types of high-strength Y-TZP had sufficient strength as implant materials even after accelerated aging treatment, therefore, clinical suitability was considered high.

\section{ACKNOWLEDGMENTS}

The authors would like to thank Mr. Yoshihiro MURAKAMI, Institute for Materials Research, Tohoku University during X-ray diffraction analysis.

\section{CONFLICT OF INTEREST}

The authors declare no conflicts of interest.

\section{REFERENCES}

1) Harada K, Shinya A, Yokoyama D, Shinya A. Effect of loading conditions on the fracture toughness of zirconia. $J$ Prosthodont Res 2013; 57: 82-87.

2) Sailer I, Gottner J, Kanel S, Hammerle CHF. Randomized controlled clinical trial of zirconia-ceramic and metal-ceramic posterior fixed dental prostheses: A 3-year follow-up. Int J Prosthodont 2009; 22: 553-560.

3) Anusavice KJ. Standardizing failure, success, and survival decisions in clinical studies of ceramic and metal-ceramic fixed dental prostheses. Dent Mater 2012; 28: 102-111.

4) Raigrodski AJ, Hillstead MB, Meng GK, Chung KH. Survival and complications of zirconia-based fixed dental prostheses: a systematic review. J Prosthet Dent 2012; 107: 170-177.

5) Oliva J, Oliva X, Oliva JD. One-year follow-up of first consecutive 100 zirconia dental implants in humans: a comparison of 2 different rough surfaces. Int J Oral Maxillofac Implants 2007; 22: 430-435.

6) Chevalier J, Cales B, Drouin JM. Low-temperature aging of Y-TZP ceramics. J Am Ceram Soc 1999; 82: 2150-2154.

7) Maria CL, Susanne SS, Patrick A, Marc J, HW Anselm W. Low-temperature degradation of a Y-TZP dental ceramic. Acta Biomater 2011; 7: 858-865.

8) Chevalier J, Drouin JM, Cales B. Low temperature aging behavior of zirconia hip joint heads. Bioceramics 1997; 10: 135-137.

9) Chevalier J, Gremillard L, Deville S. Low-temperature degradation of zirconia and implications for biomedical implants. Annu Rev Mater Res 2007; 37: 1-32.

10) Chevalier J. What future for zirconia as a biomaterial? Biomaterials 2006; 27: 535-543.

11) Tsubakino H, Satani K, Fujiwara T, Ioku S. Effect of alumina addition on the mechanical properties in partially stabilized zirconia. J Jpn Soc Powder Powder Metallurgy 2001; 48: 897901.

12) Masaki T. Mechanical properties of toughened $\mathrm{ZrO}_{2}-\mathrm{Y}_{2} \mathrm{O}_{3}$ Ceramics. J Am Ceram Soc 1986; 69: 638-640.

13) Druschitz AP, Schroth JG. Hot isostatic pressing of a presintered yttria-stabilized zirconia ceramic. J Am Ceram Soc 1989; 72: 1591-1597.

14) Iijima T, Homma S, Sekine H, Sasaki H, Yajima Y, Yoshinari M. Influence of surface treatment of yttria-stabilized tetragonal zirconia polycrystal with hot isostatic pressing on cyclic fatigue strength. Dent Mater J 2013; 32: 274-280.

15) Koyama T, Sato T, Yoshinari M. Cyclic fatigue resistance of yttria-stabilized tetragonal zirconia polycrystals with hot isostatic press processing. Dent Mater J 2012; 31: 11031110.

16) Tsubakino H. Isothermal tetragonal-to-monoclinic phase transformation in a zirconia-yttria system. Mater Tran 2005; 
17) Spies BC, Balmer M, Patzelt SB, Vach K, Kohal RJ. Clinical and patient-reported outcomes of a zirconia oral implant: three-year results of a prospective cohort investigation. $\mathrm{J}$ Dent Res 2015; 94: 1385-1391.

18) Oshima Y, Iwasa F, Tachi K, Baba K. Effect of nanofeatured topography on ceria-stabilized zirconia/alumina nanocomposite on osteogenesis and osseointegration. Int $\mathrm{J}$ Oral Maxillofac Implants 2017; 32: 81-91.

19) Takano T, Tasaka A, Yoshinari M, Sakurai K. Fatigue strength of $\mathrm{Ce}-\mathrm{TZP} / \mathrm{Al}_{2} \mathrm{O}_{3}$ nanocomposite with different surfaces. J Dent Res 2012; 91: 800-804.

20) Piconi C, Condo SG, Kosmač T. Alumina- and zirconia-based ceramics for load-bearing applications. Advanced Ceramics for Dentistry, 2014: pp. 219-253. Butterworth-Heinemann, United Kingdom.

21) Harada K, Shinya A, Gomi H, Hatano Y, Shinya A, Raigrodski AJ. Effect of accelerated aging on the fracture toughness of zirconias. J Prosthet Dent 2016; 115: 215-223.

22) Flinn BD, Raigrodski AJ, Singh A, Mancl LA. Effect of hydrothermal degradation on three types of zirconias for dental application. J Prosthet Dent 2014; 112: 1377-1384.

23) Inokoshi M, Vanmeensel K, Zhang F, De Munck J, Eliades G, Minakuchi S, et al. Aging resistance of surface-treated dental zirconia. Dent Mater 2015; 31: 182-194.

24) International Organization for Standardization. ISO13356. Implants for surgery-Ceramic materials based on yttriastabilized tetragonal zirconia (Y-TZP), 2015.

25) International Organization for Standardization. ISO1054511. Ceramictiles-Part11: Determination of crazing resistance for glazed tiles, 1994.

26) Japanese Standards Association. JIS A 5207. Sanitary wares. Japanese Standards Association. Tokyo, Japan: Japanese Standards Association; 2010. Available at: http://www.jsa. or.jp/. Last accessed November 10, 2015.

27) Huang CW, Hsueh CH. Piston-on-three-ball versus pistonon-ring in evaluating the biaxial strength of dental ceramics. Dent Mater 2011; 27: e117-123.

28) Rosenstiel SF, Gupta PK, Van der Sluys RA, Zimmerman MH. Strength of a dental glass-ceramic after surface coating. Dent Mater 1993; 9 : 274-279.

29) Kobayashi S. Anarysis methods for thin film X-ray diffraction. Rigaku J 2009; 40: 14-21. (in Japanese)

30) Shikata R, Yamamoto T, Shiono T, Nishikawa T. The degradation depth of Y-TZP specimens by aging at low temperatures. Materials 1990; 39: 1590-1595. (in Japanese)
31) Garvie RC, Nicholson PS. Phase analysis in zirconia systems. J Am Ceram Soc 1972; 55: 303-305.

32) Zhuang Y, Zhu Z, Jiao T, Sun J. Effect of aging time and thickness on low-temperature degradation of dental zirconia. Int J Prosthodont 2019; 28: e404-410.

33) Ban S, Anusavice KJ. Influence of test method on failure stress of brittle dental materials. J Dent Res 1990; 69: 17911799.

34) Shen JZ, editor. Advanced ceramics for dentistry, 1st ed. St. Louis: Butterworth-Heinemann; 2013. p.191-193.

35) Sinmazisik G, Tarcin B, Demirbas B, Gulmez T, Bor E, Ozer F. The effect of zirconia thickness on the biaxial flexural strength of zirconia ceramic bilayered discs. Dent Mater J 2015; 34: 640-647.

36) Cheng M, Chen W, Sridhar KR. Biaxial flexural strength distribution of thin ceramic substrates with surface defects. Int J Solids Struct 2003; 40: 2249-2266.

37) International Organization for Standardization ISO 14801: 2016. Dentistry -Implants - Dynamic fatigue test for endosseous dental implants 2016.

38) Matsuzaki F, Sekine H, Honma S, Takanashi T, Furuya $\mathrm{K}$, Yajima Y, et al. Translucency and flexural strength of monolithic translucent zirconia and porcelain-layered zirconia. Dent Mater J 2015; 34: 910-917.

39) Inokoshi M, Zhang F, Vanmeensel K, De Munck J, Minakuchi $\mathrm{S}$, Naert I, et al. Residual compressive surface stress increases the bending strength of dental zirconia. Dent Mater 2017; 33: e147-154.

40) Swain MV. Grinding-induced tempering of ceramics containing metastable tetragonal zirconia. J Mater Sci Lett 1980; 15: 1577-1579.

41) Siarampi E, Kontonasaki E, Andrikopoulos KS, Kantiranis $\mathrm{N}$, Voyiatzis GA, Zorba T, et al. Effect of in vitro aging on the flexural strength and probability to fracture of Y-TZP zirconia ceramics for all-ceramic restorations. Dent Mater 2014; 30: e306-316.

42) Munoz-Tabares JA, Anglada M. Hydrothermal degradation of ground 3Y-TZP. J Eur Ceram Soc 2012; 32: 325-333.

43) Fontijn-Tekamp FA, Slagter AP, Van Der Bilt A, Van 'T Hof MA, Witter DJ, Kalk W, et al. Biting and chewing in overdentures, full dentures, and natural dentitions. J Dent Res 2000; 79: 1519-1524.

44) Takamizawa T. Studies on the co-relative and individual biting forces of normal permanent teeth. J J Prosthet Soc 1965; 9: 217-236. (in Japanese) 